\title{
A noção de couraça na obra de Wilhelm Reich: publicações de 1920 a 1933
}

\author{
Bruno Prates Almeida', Paulo Albertini \\ Instituto de Psicologia, Universidade de São Paulo, São Paulo, SP, Brasil
}

Resumo: Este estudo investiga a noção de couraça nos primeiros 13 anos, de 1920 a 1933, da obra do analista Wilhelm Reich (1897-1957), período em que o autor esteve vinculado à International Psychoanalytical Association. A questão norteadora é: qual(ais) o(s) sentido(s) da couraça no pensamento de Reich? Foram pesquisados os escritos do então psicanalista de acordo com a sequência cronológica de publicação dos trabalhos. Encontrou-se que: a) a couraça é mencionada pela primeira vez em 1922, no artigo "Dois tipos narcisistas", para indicar uma defesa associada ao quadro das neuroses de caráter; b) a princípio, ela é concebida na esfera psíquica, mas, gradativamente, passa a ser considerada também no âmbito somático; c) destinada a exercer função protetora, a couraça constitui algo natural e inevitável, porém essa estrutura pode chegar a comprometer o contato com o meio interno e externo, além de afetar a regulação libidinal do sujeito.

Palavras-chave: Reich, Wilhelm, 1897-1957, couraça, caráter, psicanálise.

\section{Introdução}

O austro-húngaro Wilhelm Reich (1897-1957) participou ativamente do movimento psicanalítico na década de 1920 e início da de 1930 (Weinmann, 2002). Sempre visando contribuir para a melhoria das condições de vida humana, esse cientista militante deixou escritos voltados para diferentes áreas do saber (Albertini, 2011).

Neste artigo, enfocamos, especificamente, uma produção reichiana germinada em solo psicanalítico: a noção de couraça. Nosso principal objetivo foi acompanhar e explicitar o processo de construção desse conceito por meio de uma investigação das publicações do autor efetuadas de 1920 a 1933, período em que Reich esteve vinculado à International Psychoanalytical Association (IPA). Cabe observar que em 1934, no $13^{\circ}$ Congresso Internacional de Psicanálise, realizado em Lucerna, na Suíça, ocorreu a polêmica expulsão de Reich da IPA (Jones, 1979; Reich, 1953/1976; Wagner, 1996).

Sabe-se que a noção de couraça perpassa boa parte das publicações do teórico. Dada sua relevância em escritos de comentadores do pensamento reichiano, o termo tem sido largamente mencionado com diferentes graus de exposição. Tal fato pode ser verificado em livros amplamente difundidos, como Nos caminhos de Reich (Boadella, 1985) e Cien flores para Wilhelm Reich (Dadoun, 1978).

Também em pesquisas científicas recentes, a noção de couraça não deixa de ser focalizada e discutida. Isso ocorre, por exemplo, nos trabalhos: $O$ desenvolvimento $d a$ noção de caráter no pensamento de Reich (Silva, 2001); A vida é dura para quem é mole: considerações sobre

1 Autor correspondente: bruno@ericom.com.br aspectos psicológicos da hipotonia muscular (Rego, 2008); A couraça como currículo-oculto: um estudo da relação entre a rotina escolar e o funcionamento encouraçado (Garcia, 2010). Porém, nessa área de investigação, não constatamos a presença de qualquer estudo centrado no processo de construção da noção de couraça. Assim sendo, como contribuição a esse campo de trabalhos, tendo como base a sequência cronológica das publicações reichianas, procuramos identificar e comentar o que o autor vai formulando a respeito desse assunto nos primeiros 13 anos de sua obra.

Como procedimento de pesquisa, de posse da sequência cronológica das publicações de Reich - para isso nos pautamos em Organização bibliográfica da obra de Wilhelm Reich: bases para o aprofundamento em diferentes áreas do conhecimento (Matthiesen, 2007) -, caminhamos de 1920 até 1933, sempre tendo como meta apreender o que o autor vai elaborando sobre o assunto. Mais especificamente, em um primeiro passo, identificamos os escritos de Reich publicados no período em tela. A seguir, analisamos o conteúdo dos 37 textos que conseguimos ter acesso e chegamos a um número de 15 trabalhos, os que, segundo nossa leitura, contêm contribuições à conceituação de couraça.

Segue, em ordem cronológica de publicação original, a relação dos 15 trabalhos que foram objeto de nossa análise: "Dois tipos narcisistas" (Reich, 1922/1975); "A atitude dos pais a respeito do onanismo infantil" (Reich, 1927/2008); "Psicopatologia e sociologia da vida sexual" (Reich, 1927/1977a); "Sobre a técnica de interpretação e de análise da resistência" (Reich, 1927/2001b); "Sobre a técnica de análise do caráter" (Reich, 1928/2001c); "O caráter genital e o caráter neurótico: a função econômica-sexual da couraça do caráter" (Reich, 1929/2001d); "Materialismo 
dialético e psicanálise" (Reich, 1929/1977b); "A fobia infantil e a formação do caráter" (Reich, 1930/2001e); "O caráter masoquista" (Reich, 1932/2001f); "Irrupção da moral sexual repressiva" (Reich, 1932/n.d.); "Indicações e perigos da análise do caráter" (Reich, 1933/2001g); "Sobre o manejo da transferência" (Reich, 1933/2001h); "A solução caracterológica do conflito sexual infantil" (Reich, 1933/2001i); "Algumas formas definidas de caráter" (Reich, 1933/2001j); "Psicologia de massa do fascismo" (Reich, 1933/1974).

Como aproximação ao tema, vale mencionar que Wilhelm Reich redigiu a maior parte da sua obra em alemão e outra parte em inglês. Especificamente de 1920 a 1933, todos os trabalhos foram publicados em alemão. Em sua língua materna, o autor empregou o termo Panzer, que tem um forte sentido de proteção, como, por exemplo, em animais (Schildkrotenpanzer - casco de tartaruga); outro possível significado para Panzer é tanque de guerra. No período investigado, no que diz respeito à noção de couraça, um material fundamental é o livro Análise do caráter (Reich, 1933/2001a). Pesquisando no original Charakteranalyse (Reich, 1933/1970), verificamos que o autor utilizou outras expressões além de Panzer. Uma delas é Charakterpanzer, que admite as traduções como couraça do caráter ou blindagem do caráter. Outra forma utilizada é Panzerung, significando o processo de encouraçamento ou blindagem, tal qual em Panzerung des Ichs, traduzido para o português como encouraçamento do ego ou blindagem do ego. Encontramos também a expressão Muskuläre Panzerung, vertido como encouraçamento muscular. Já em inglês, o autor utilizou o vocábulo armor, que pode ser traduzido por armadura.

Na língua portuguesa, a tradução mais corrente encontrada é couraça, termo derivado do latim cŏrĭum que admite, segundo o Dicionário etimológico da língua portuguesa (Cunha, 2009) duas significações: couro - pele espessa e/ou curtida de certos animais; coura(ça) - antigo gibão de couro usado pelos guerreiros. No dicionário Houaiss (2004) há três significados que nos interessam, a saber: armadura para proteção do tronco dos soldados, de couro ou metal; p.ext.fig. mecanismo de defesa; conjunto de placas ou escamas ósseas que revestem o corpo de certos animais.

Constatamos que os significados encontrados nas três línguas apontam para o sentido de defesa, seja por meio de defesas orgânicas próprias de algumas espécies animais (escamas, casco), ou com roupas de couro e/ou metal. Há também o sentido figurado de um mecanismo de defesa, o que possibilita uma leitura psicológica da couraça.

A exposição deste trabalho foi organizada em dois tópicos: no primeiro, tendo como foco a noção de couraça, o leitor encontrará uma análise dos primeiros 13 anos da produção reichiana; no segundo, as considerações finais deste estudo.

\section{A noção de couraça na produção reichiana de 1920 a 1933}

Neste tópico, a ordem de exposição acompanha a sequência histórica das publicações. Tendo por base os 15 escritos analisados, a fim de evitar repetições, utilizamos como critério apresentar conteúdos que contenham alguma novidade em relação ao já mencionado.

Em "Dois tipos narcisistas" (Reich, 1922/1975), o ainda jovem psicanalista (25 anos) refere-se a uma usual diferenciação entre as neuroses sintomáticas - um quadro clínico constituído por sintomas claros e bem definidos (egodistônicos) - e as neuroses de caráter, que apresentam sintomas difusos e mesclados ao modo particular de ser do indivíduo (egossintônicos). É no terreno nosológico das neuroses de caráter que a couraça narcísica é mencionada. Segundo o autor, "como uma regra, a armadura narcísica aparece mais cedo ou mais tarde e requer toda a habilidade do analista para ser penetrada" (p. 136, itálicos nossos). Cabe informar que o texto consultado em nossa pesquisa é uma versão em inglês e o termo usado foi narcissistic armor, traduzido como armadura narcísica. No entanto, levando em consideração a questão das traduções, o consideramos equivalente à couraça narcísica.

Inicialmente, Reich expõe a estrutura de um paciente que apresenta, prioritariamente, sentimentos de inferioridade, porém, essa frequente expressão autodepreciativa, como bem indica Silva (2001), encobre um ideal de ego superinvestido, uma desproporcional valorização de si. Já o segundo tipo de caráter contém uma outra configuração defensiva. Neste, ocorreria uma manifestação exagerada de superioridade, uma tentativa de contrabalancear os sentimentos latentes de inferioridade, muitas vezes inconscientes. Esse sujeito superestima e superinveste o ego real, inflando-o. Mais especificamente, a expressão de superioridade atuaria como uma couraça narcísica para evitar o contato com os sentimentos de inferioridade decorrentes do complexo de castração. O autor ressalta, ainda, os diferentes momentos em que a couraça atua em cada tipo narcísico apresentado. Para ele, "em contraste com os representantes do complexo de inferioridade manifesta, onde a armadura narcísica aparece tardiamente no tratamento, os casos de inferioridade latente manifestam tal armadura logo no início" (Reich, 1922/1975, p. 138). No decorrer do artigo, é notória a indicação de que, nos dois casos, a couraça narcísica deve ser focalizada na análise, pois essa formação defensiva atuaria como resistência e a favor do equilíbrio neurótico.

Portanto, nesse artigo de 1922, a expressão couraça narcísica é empregada por Reich para indicar a presença de defesas egossintônicas que desempenham o papel de acobertar determinados conteúdos psíquicos. Trata-se de uma forma de proteção que tende a acompanhar as neuroses de caráter, entretanto, como o autor considera que "não há neurose, não importa quão claramente definida, sem traços de um distúrbio de toda a personalidade" (Reich, 1922/1975, pp. 134-135), podemos supor que essa formação defensiva também se faça presente, de alguma maneira, nas chamadas neuroses sintomáticas.

Cinco anos depois, em "Sobre a técnica de interpretação e de análise da resistência", Reich (1927/2001b) expõe de forma didática e em detalhes a sua principal contribuição 
para o campo da técnica psicanalítica, a Análise do Caráter. No texto, em uma das exemplificações citadas, ele relata que atendeu um sujeito que esteve em tratamento analítico com um colega. Na análise com Reich, após quatro meses de atividade, como as interpretações realizadas não surtiam qualquer efeito no paciente, a análise foi interrompida, supostamente devido às resistências não trabalhadas no início do processo. Refletindo sobre esse insucesso clínico, o autor pondera que "é possível que uma interpretação mais demorada e mais consistente da defesa narcísica do paciente tivesse dado algum resultado" (Reich, 1927/2001b, p. 38, itálicos nossos).

Percebe-se que Reich utiliza diferentes terminologias, mas parece estar fazendo referência à mesma função. Fica a impressão de que a couraça narcísica - que resiste a qualquer intervenção externa sentida como uma ameaça à estrutura neurótica - equivale à "defesa narcísica", expressão empregada no trecho citado. Além disso, há um apontamento no sentido de que algo deveria ser desarticulado, ou removido, com o intuito de dar passagem às interpretações analíticas. No que diz respeito à orientação clínica sugerida por Reich, destaca-se a indicação a respeito da necessidade de uma análise consistente da resistência, um ponto nodal da técnica da Análise do Caráter (Etchegoyen, 1989).

Ainda no mesmo artigo, o autor destaca que alguns maneirismos típicos do sujeito funcionam como meios de proteção e, portanto, como resistência ao tratamento. Ao discorrer a respeito de um indivíduo polido e gentil, alerta que "a experiência analítica ensina que, por baixo dessa polidez e gentileza, está sempre escondida uma atitude ... de desconfiança ou de depreciação" (Reich, 1927/2001b p. 42, itálicos originais). O caso versa sobre a chamada polidez estereotipada em um paciente que produz material e dados que contrariariam qualquer desconfiança de resistência presente. Reich se atenta para elementos que vão além do conteúdo, ressaltando, também, a forma como são expressos. Para ele, "o neurótico tem todas as razões, devido à sua repressão, para dar um valor especialmente alto à polidez e às convenções sociais e fazer uso delas como meios de proteção" (p. 42).

No ano seguinte, dando continuidade à sua exposição da Análise do Caráter, Reich (1928/2001c) publica o artigo "Sobre a técnica de análise do caráter". Neste, merece destaque a articulação que o autor promove entre as neuroses sintomáticas e as de caráter. Tal elaboração é fundada na tese, de certa maneira implícita em "Dois tipos narcisistas" (Reich, 1922/1975), de que toda neurose sintomática está assentada em um caráter neurótico, o que implica que os sintomas constituiriam uma espécie de cume de toda uma montanha comprometida. Com essa leitura conceitual, não faz mais sentido que o trabalho analítico focalize apenas a análise dos sintomas, ele deve necessariamente ser ampliado a fim de abranger a estrutura neurótica como um todo.

De acordo com essa elaboração, tanto nas neuroses sintomáticas, como nas de caráter, os traços de caráter neuróticos configurariam um condensado mecanismo de defesa, qual seja, a couraça de caráter. Tal estrutura defensiva egossintônica, pelo gasto de energia efetuado para sua manutenção e funcionamento, implicaria num determinado controle da libido. Além disso, no processo de análise, essa formação atuaria como resistência. Nas palavras do autor:

A totalidade dos traços de caráter neuróticos manifesta-se na análise como um compacto mecanismo de defesa contra nossos esforços terapêuticos, e quando remontamos analiticamente à origem dessa "couraça" de caráter vemos que ela tem, também, uma função econômica definida. Tal couraça serve, por um lado, de proteção contra os estímulos externos e, por outro, consegue ser um meio de obter controle sobre a libido, que está continuamente pressionando desde o id, pois a energia libidinal e sádica é gasta nas formações reativas neuróticas, nas compensações etc. (Reich, 1928/2001, p. 56, itálicos e aspas originais)

Nesse fragmento, Reich expõe uma série de aspectos a respeito da sua visão de couraça. Para o autor, trata-se de um tipo de proteção contra estímulos externos, ao mesmo tempo em que essa formação controla e consome uma cota de energia libidinal e sádica. Tal estrutura defensiva ajuda a estabelecer um equilíbrio, mesmo que neurótico, e a análise é sentida como uma ameaça a esse estado. Também nesse mesmo texto, salientando o papel defensivo presente, o autor afirma que "a couraça do caráter é a expressão concreta da defesa narcísica cronicamente implantada na estrutura psíquica" (Reich, 1928/2001, p. 59, itálicos originais). Ou seja, Reich emprega a expressão "couraça do caráter" para indicar as defesas crônicas presentes no caráter neurótico.

Em acordo com a perspectiva técnica da análise do caráter, o analista deve buscar meios para desarticular os funcionamentos defensivos neuróticos do paciente, e isso significa realizar um trabalho consistente e direto com a couraça do caráter. Essa investida tem objetivos definidos e apontados pelo autor:

o resultado imediato do afrouxamento analítico da couraça de caráter e da ruptura do aparelho de defesa narcísico tem dupla face: 1) A liberação dos afetos de suas ancoragens e disfarces; 2) $O$ estabelecimento de uma entrada para a área central do conflito infantil - o complexo de Édipo e a angústia de castração. (Reich, 1928/2001, p. 84, itálicos originais)

Podemos perceber que o então analista se ocupava, primeiramente, do trabalho com os aspectos defensivos neuróticos que atuam como resistência antes de interpretar materiais inconscientes profundos. Para ele, essa sistematização do trabalho analítico evitaria situações caóticas posteriores. 
Um ano depois, em 1929, Reich publica o artigo "O caráter genital e o caráter neurótico: a função econômicosexual da couraça do caráter" (1929/2001d), um artigo, como o título sugere, rico em considerações a respeito da noção de couraça e voltado para o delicado tema das concepções de saúde e doença no campo da psicanálise. De início, vale citar o alerta efetuado pelo autor acerca do eixo principal do estudo. Aparentemente preocupado com possíveis apreensões que promovam uma separação artificial entre saúde e doença, ele afirma: "em termos de suas diferenças qualitativas, os caracteres neuróticos e genitais devem ser entendidos como tipos básicos. Os caracteres reais representam uma mistura" (Reich, 1929/2001d, p. 172).

No escrito, ainda em seu terço inicial, discorrendo sobre as defesas empregadas pelos seres vivos, Reich afirma: "Freud ensinou-nos a conceber o ego, isto é, a parte do mecanismo psíquico dirigida para o mundo externo, e por isso mesmo exposta, como um aparelho preparado para aparar estímulos" (Reich, 1929/2001d, p. 166). A seguir, acrescenta: "Freud descreveu, de maneira muito clara, a luta que o ego, como um para-choque entre o id e o mundo externo (ou o id e o superego) tem de assumir" (Reich, 1929/2001d, p. 166).

Cabe observar que nessas duas menções a Freud, Reich refere-se a uma específica elaboração do psicanalista vienense: a "proteção contra estímulos" (no original alemão, Reizschutz ${ }^{2}$ ), termo introduzido pelo autor no escrito Além do princípio do prazer (Freud, 1920/2010). No referido texto freudiano, em uma parte dedicada à teorização sobre o trauma, o mestre psicanalista imagina o que ocorreria com um organismo simples, uma vesícula de substância excitável, se não dotada de uma estrutura protetora: "Esse pequeno pedaço de substância viva flutua num mundo externo carregado de fortes energias, e seria liquidado pela ação dos estímulos que vêm dele se não fosse dotado de uma proteção contra estímulos" (Freud, 1920/2010, p. 188; itálicos originais). Ainda se reportando a uma vesícula viva, ele observa que, em busca de proteção "sua superfície mais exterior perde a estrutura própria do que vive, tornase inorgânica em certa medida, e funciona como um invólucro ou membrana especial que detém estímulos (Freud, 1920/2010, p. 188).

Com base nas citadas menções de Reich e no exposto sobre a proteção contra estímulos de acordo com Freud, difícil não pensar em um trabalho que discuta as relações entre a noção de couraça, em Reich, e o Reizschutz freudiano. Como essa palpitante proposta escapa aos objetivos deste artigo, fiquemos com a compreensão de que Reich parte de uma visão de defesa como algo necessário e natural. Para isso, dentre outros conteúdos, o autor reporta-se à noção de proteção contra estímulos formulada por Freud.

2 Em português, além de "proteção contra estímulos", o termo Reizschutz tem recebido outras traduções, por exemplo: "para-excitações", em Laplanche e Pontalis (1983, p. 421), e "escudo protetor", na edição da editora Imago das obras de Freud.
De posse do entendimento de que a construção de defesas constitui algo que acompanha os seres vivos, Reich passa a discutir a relação entre a defesa empregada e a limitação decorrente da presença de tal estrutura. Com esse prisma de análise, argumenta que as defesas podem apresentar diferentes graus de rigidez e cronicidade, sendo, a seu ver, o polo da saúde composto por defesas mais flexíveis e menos permanentes. Nesse ponto, lançando mão de exemplos do campo da biologia, o autor observa que há protozoários "que se protegem do rude mundo externo com uma couraça de material inorgânico formado por excreções químicas do protoplasma" (Reich, 1929/2001d, p. 167). Em outro trecho, ao estabelecer uma comparação entre a ameba e determinados protozoários, ele aponta a limitação que acompanha o segundo grupo. De acordo com o escrito:

Comparada com a da ameba, a mobilidade desses protozoários encouraçados é consideravelmente limitada; o contato com o mundo externo é limitado aos pseudópodos que, para sua locomoção e nutrição, podem ser estendidos e retraídos novamente através dos pequenos buracos da couraça. (Reich, 1929/2001d, p. 167)

A partir do que foi aqui apresentado, teceremos uma consideração voltada para as ideias de outro autor muito caro a Reich: o filósofo francês contemporâneo Henri Bergson (1859-1941). Vale observar que em sua biografia científica A função do orgasmo: problemas econômicosexuais da energia biológica, Reich (1942/1995) manifesta ter sido tocado profundamente pela abordagem de Bergson e conta ter feito "um estudo muito cuidadoso dos seus Matter and Memory, Time and Freedom e Creative Evolution" (Reich, 1942/1995, p. 29, itálicos originais).

Em $A$ evolução criadora, o filósofo francês supõe que a vida é governada por um princípio vital, o élan vital. Para o autor, "o papel da vida consiste em inserir indeterminação na matéria" (Bergson, 1907/1971, p. 144), o que implica um processo contínuo de criação de formas, a evolução criadora. Como contraponto, a matéria, por sua vez, tende à cronicidade de formas, o que resulta na aparição de hábitos e automatismos capazes de limitar as expressões do impulso vital.

Ainda de acordo com o pensador francês, o processo de adaptação das espécies traz consigo a necessidade de se desenvolver estruturas de defesa. Essa condição biológica de sobrevivência, em alguns animais, tem como consequência o aparecimento de invólucros ósseos, conchas, carapaças e couraças. ${ }^{3}$ Tais formações protegem, porém limitam os movimentos das espécies que as desenvolveram.

Se parearmos o enfoque do pensador francês com o prisma teórico assumido por Reich no que se refere à noção de couraça, pelo menos no que diz respeito ao período

3 Bergson faz amplo uso do termo cuirasse, próximo de couraça em português, e, também, carapace, traduzido por carapaça. 
abrangido por esta pesquisa, veremos que estamos, digamos, no mesmo campo de sentidos: um domínio que entende como natural e necessária a criação de estruturas protetoras, como uma categoria de proteção biológica; a consideração das consequências limitadoras, restritivas e cronificadoras decorrentes do desenvolvimento de formações endurecidas e o apontamento para os ganhos alcançados por estruturas protetoras móveis no reino animal.

Como base nessas observações e visando fomentar esse campo de investigação, cabe lançar as seguintes questões: será plausível supor que Reich opera com uma visão de couraça que carrega marcas do pensamento de Henri Bergson? Se sim, em que medida? No entanto, assim como no caso do Reizschutz freudiano, é necessário outro trabalho investigativo para tal conjectura. De qualquer maneira, não nos parece exagero considerar a hipótese de que o olhar reichiano para a existência de uma couraça biológica pode encontrar sua matriz no pensamento bergsoniano.

Dando continuidade à elaboração conceitual, ainda no texto de 1929, Reich discorre a respeito dos aspectos quantitativos e qualitativos da couraça do caráter e, para isso, supõe duas possibilidades. Em uma configuração, o "encouraçamento do caráter" ocorreria em um "grau compatível com o desenvolvimento da libido" (Reich, 1929/2001d, p. 169) e isso indica que haveria possibilidades de contato e de afastamento do âmbito externo. Denominada como caráter genital, nessa estrutura:

o ego é muito acessível tanto ao prazer (lust) como ao desprazer (unlust). O ego também apresenta uma couraça, mas ele a controla, não está a sua mercê. A couraça é flexível o bastante para se adaptar às mais diversas experiências. (Reich, 1929/2001d, p. 175)

Merece destaque nesse fragmento, a indicação reichiana no sentido da possibilidade de contato tanto com o prazer, quanto com o desprazer, em uma espécie de sensibilidade aberta às diversas circunstâncias inerentes ao viver. Apontamento básico, porém não enfatizado em visões estereotipadas sobre o autor, marcadas, a nosso ver quase que exclusivamente, pelo laço entre a saúde e a capacidade de experimentar o prazer.

Nessa apresentação e discussão de características e potências do caráter genital, fica destacada, por exemplo, a possibilidade de lidar de maneira direta com diferentes emoções, por um lado sem precisar negá-las e, por outro, sem ficar subjugado pelas mesmas. Para o teórico, "a flexibilidade e a força de sua couraça se evidenciam pelo fato de, em um caso, ele se abrir ao mundo de modo tão intenso quanto, em outro, se fechar a este" (Reich, 1929/2001d, p. 175). Parece indicar uma capacidade de manter um fluxo entre abrir e fechar, tensionar e relaxar, carregar e descarregar, por meio de um uso saudável da couraça. É importante lembrar que, na perspectiva reichiana, a exposição dos caráteres genital e neurótico objetiva traçar um protótipo, algo como um direcionamento.
A respeito do outro polo, o do caráter neurótico e sua couraça, Reich destaca o aspecto econômico, salientando que "é provável que cada conversão permanente da libido objetal em libido narcísica ande de mãos dadas com o fortalecimento e enrijecimento da couraça do ego" (Reich, 1929/2001d, p. 170). Podemos notar que o autor retoma, de certa maneira, o assunto discutido no texto de 1922 ("Dois tipos narcisistas"), por um viés econômico, dado que haveria, nos dois tipos narcisistas relatados, um exacerbado investimento libidinal no próprio ego ou no ideal de ego. Ao que nos parece, essa condição é atribuída ao caráter neurótico, no qual o encouraçamento do ego torna as brechas com o mundo externo muito limitadas. Para o autor, uma vez "que a agressividade está incorporada ou, mais especificamente, ancorada parcialmente na couraça do caráter e parcialmente no superego, as realizações sociais são prejudicadas" (p. 177). Além disso, pondera que as realizações sociais seriam também prejudicadas em decorrência da limitada flexibilidade da estrutura de defesa presente, pois "a rigidez de sua couraça o impede tanto de se abrir a alguma experiência particular como de se fechar completamente a outras experiências em que seria racionalmente justificado fazê-lo" (p. 177).

Em síntese, a análise de "O caráter genital e o caráter neurótico: a função econômico-sexual da couraça do caráter" (Reich, 1929/2001d), um trabalho repleto de contribuições a respeito da conceituação de couraça, permite as seguintes observações nucleares: a) ao focalizar o tema do natural aparecimento de defesas nos seres vivos, Reich reporta-se, dentre outros conteúdos, à formulação freudiana da proteção contra estímulos (Reizschutz) e a exemplos de couraças biológicas, sua importância e consequências, próximas àquelas presentes na obra de Bergson; b) em se tratando de uma estrutura defensiva mais próxima ao polo da saúde, o autor vislumbra a possibilidade do desenvolvimento de uma couraça flexível; c) no escrito em tela, a noção de couraça passa a indicar, além da dimensão psíquica, a presença de uma formação biológica, concreta; d) em uma formulação mais completa, pode-se dizer que, destinada a exercer função protetora, a couraça constitui algo natural e inevitável, porém, dependendo do seu grau, ela pode comprometer o contato com o meio interno e externo, além de afetar a regulação libidinal do sujeito.

Já no artigo "A solução caracterológica do conflito sexual infantil" - apresentado no ano de 1930, em Dresden, no Congresso da Sociedade Psicanalítica Alemã, e publicado em 1933 (Reich, 2001i), em determinado trecho, tece uma costura entre as noções de ego, caráter e couraça que, dado o objetivo desta pesquisa, merece ser citada. De acordo com o autor:

O caráter consiste numa mudança crônica do ego que se poderia descrever como um enrijecimento. Esse enrijecimento é a base real para que o modo de reação característico se torne crônico; sua finalidade é proteger o ego dos perigos internos e externos. Como uma formação protetora que se tornou 
crônica, merece a designação de encouraçamento, pois constitui claramente uma restrição à mobilidade psíquica da personalidade como um todo. (Reich, 1933/2001i, p. 151)

Vale assinalar que, focalizando o caráter neurótico, Reich menciona a ocorrência de um encouraçamento excessivo e, porque não, aprisionador. Em sentido amplo, o autor parece apontar para uma mudança de estado, particularmente, a passagem de um estado móvel e flexível, para um fixo e enrijecido. Ainda mais especificamente, é possível entender que Reich está procurando indicar a ocorrência de um processo em que uma necessária formação protetora, o caráter, torna-se endurecida e crônica. Dado esse resultado, o sujeito tende a apresentar o mesmo padrão de reação, um procedimento típico, algo que pouco se altera em função das circunstâncias externas. Assim sendo, pode-se dizer que uma formação defensiva, algo importante e necessário para a proteção da vida, passível de ser ativada em situações de ameaça ou perigo, não pode mais ser desativada, mesmo em contextos afáveis e amistosos. Em outras palavras, na visão do autor, o ser humano encouraçado não consegue mais controlar suas defesas, pois elas tornaram-se uma estrutura fixa e automática, uma armadura que protege ao mesmo tempo que limita o potencial de ações no mundo e, mais além, implica num gasto de energia para a sua manutenção. A análise do caráter se constitui enquanto ferramental técnico e terapêutico eficaz para a desarticulação da couraça do caráter e eficiente no posterior trabalho com conteúdos emergentes de tal afrouxamento.

A edificação da couraça se dá na interação dos âmbitos interno e externo e o teórico salienta aspectos que interferem, inclusive, no âmbito da educação. Ele alerta que

se, por um lado, esse encouraçamento tem pelo menos sucesso temporário ao evitar estímulos pulsionais internos, por outro, constitui forte bloqueio não só contra estímulos externos, mas também contra influências educacionais posteriores. (Reich, 1933/2001i, p. 154)

Ainda nesse escopo educacional, o teórico adverte sobre a moral sexual vigente na época e como a mesma dificultava - e até impossibilitava - uma educação que levasse em conta as pulsões sexuais infantis. Além disso, ele enumera várias outras condições influentes na formação do caráter, tais como a fase na qual a pulsão é frustrada, a frequência, a intensidade etc. Sua preocupação com o âmbito sociocultural e econômico e seus elementos inevitavelmente presentes nessa interação com o organismo pulsional é notória, pois considera que "todas essas questões são determinadas pela ordem social dominante no que diz respeito à educação, moralidade e satisfação das necessidades, em última análise, pela estrutura econômica vigente da sociedade" (Reich, 1933/2001i, p. 156). É perceptível, portanto, o amplo olhar reichiano para as questões implicadas na formação de encouraçamentos ditos patológicos.
Apesar das consequências limitantes da couraça, como restrições na mobilidade psíquica, o então psicanalista pondera que algumas relações com o mundo externo escapam a esse aprisionamento caracterológico, abrindo possibilidades. Nessa linha de entendimento, ele afirma que são como "brechas na couraça através das quais, segundo a situação, interesses libidinais e outros são enviados para fora e novamente puxados para dentro como pseudópodes" (Reich, 1933/2001i, p. 151). Interessante notar como Reich, ao lançar mão de exemplos advindos da biologia, acaba se aproximando do referencial bergsoniano da couraça no reino animal. Nos dois pensadores, encontraremos a noção de defesa que protege, mas restringe a mobilidade, ou seja, alguma coisa que, ao mesmo tempo, é necessária e traz consequências limitadoras de outros potenciais.

Pode-se afirmar que o artigo em tela dá continuidade ao trabalho "O caráter genital e o caráter neurótico" (Reich, 1929/2001d), especialmente no que se refere à teorização voltada para a exposição e análise dos polos saúde e doença, tendo por base a tese de que tais polos constituem apenas modelos hipotéticos, parâmetros situados nos extremos de um mesmo continuum. Além disso, merece destaque o fato de Reich lançar mão de analogias do campo da biologia e construir imagens marcadas pela concretude, em uma clara alusão à formação de uma estrutura protetora que, além da dimensão psíquica, comporta, também, uma esfera somática. Diante dessa complexa investida em localizar a couraça em meio à estruturação do sistema psíquico, o autor aponta que "é em torno do ego que essa couraça se forma, em torno precisamente daquela parte da personalidade que se situa na fronteira entre a vida pulsional biofisiológica e o mundo exterior. Por isso a designamos como caráter do ego" (Reich, 1933/2001i, p. 152, itálicos originais). Mais uma vez o importante entrelaçamento entre ego-caráter-couraça se faz presente, no qual a última é posta como uma espécie de capa ou revestimento, localizada nessa fronteira entre os mundos interno e externo, expressa por meio dos traços de caráter.

Ainda em 1933, no capítulo "Algumas formas definidas de caráter" (Reich, 1933/2001j), que integra o livro Análise do caráter, Reich se propõe a discutir os caráteres histérico, compulsivo e fálico-narcisista, muitas vezes comparando-os no intuito de, pelas diferenças, encontrar as peculiaridades de cada um. Em termos gerais, considera que "a forma externa desse encouraçamento é sempre historicamente determinada" (p. 197). Nessa linha de formulação, mesclando observações sobre aspectos físicos e psíquicos, ele afirma: "A expressão facial e o modo de andar do caráter histérico nunca são rígidos e pesados, como no caráter compulsivo; nunca são arrogantes e autoconfiantes, como no caráter fálico-narcisista" (p. 198).

Para os objetivos desta investigação, cabe chamar a atenção para o amplo e detalhado olhar sobre o corpo efetuado pelo autor ao discorrer a respeito da estrutura compulsiva. Na verdade, uma perspectiva sintonizada com a progressiva ampliação do enfoque reichiano visando 
circunscrever as formas de defesa somáticas em suas elaborações sobre a couraça. No texto:

O bloqueio de afetos representa um enorme espasmo do ego, que faz uso das condições espasmódicas somáticas. Todos os músculos do corpo, mas especialmente os do assoalho pélvico e da pelve, os músculos dos ombros e da face (note-se fisionomia "dura", quase uma máscara, dos caracteres compulsivos), estão num estado de hipertonia crônica. (Reich, 1933/2001j, p. 206)

Nessa acurada descrição a respeito dos aspectos somáticos da estrutura obsessiva, a percepção reichiana aponta para a massiva predominância do estado de hipertonia muscular. Essa aguda sinalização, pelo que contém de clareza e novidade, merece um comentário. De acordo com o que já foi exposto neste trabalho, o polo da saúde seria representado por estruturas mais flexíveis - formações pouco marcadas pela rigidez e cronicidade -, ou seja, a nosso ver, Reich está indicando a possibilidade de alternar estados, isso tendo em vista o estabelecimento de um contato sensível com o meio interno e externo. Aplicando esse mesmo ângulo de análise à dimensão corporal, a saúde seria a possibilidade de endurecer e relaxar, conter e soltar.

Antes de finalizarmos este tópico, ainda nesse tema dos aspectos somáticos da couraça, gostaríamos de registrar a hipótese de que o protótipo de defesa da estrutura obsessiva - uma formação marcada pelo bloqueio de afetos por meio de uma ampla hipertonia muscular crônica - acabou por marcar as representações a respeito da couraça no campo das práticas e dos estudos fundados no referencial reichiano. Como não temos dados de pesquisas para referendar tal conjectura, trata-se apenas de uma suposição a ser investigada. Já em relação ao assunto couraça e hipotonia muscular, o leitor pode encontrar uma pertinente discussão no estudo A vida é dura para quem é mole: considerações sobre aspectos psicológicos da hipotonia muscular (Rego, 2008).

\section{Considerações finais}

Segundo os achados desta pesquisa, Reich, de forma inaugural, empregou o termo couraça, mais especificamente como "couraça narcísica", no artigo publicado em 1922, "Dois tipos narcisistas" (Reich, 1975). Portanto, ainda jovem (25 anos) e dois anos após ter se vinculado à Sociedade Psicanalítica. Cabe registrar que o estudo de Silva (2001) já indicara a presença da expressão couraça narcísica no referido artigo reichiano. De nossa parte, de acordo com o método utilizado nesta investigação - acompanhar a sequência histórica das publicações de Reich - e tendo como fundamento os escritos que conseguimos ter acesso, acrescentamos que essa foi a primeira vez que o autor utilizou em sua obra o termo couraça.

Em "Dois tipos narcisistas" (Reich, 1922/1975), a expressão couraça narcísica aparece associada ao quadro das neuroses de caráter. Nesse domínio, ela indica a presença de uma formação psíquica egossintônica, que contém uma cota libidinal e opera a favor da manutenção do equilíbrio neurótico. No caso de um atendimento analítico, pelo fato dessa defesa barrar o acesso a determinados conteúdos psíquicos, ela vai se constituir em uma importante fonte de resistência. Já nos escritos reichianos voltados à exposição de sua proposta técnica para o campo da clínica psicanalítica - a Análise do Caráter - a couraça passa a ser apontada como uma formação defensiva vinculada à esfera das neuroses em geral. Tal abrangência está baseada no entendimento de que toda neurose sintomática está assentada em uma estrutura que também comporta traços neuróticos egossintônicos - uma linha conceitual suposta, mas não desenvolvida em "Dois tipos narcisistas".

Por meio da análise dos escritos reichianos, de acordo com a sequência das publicações, foi também possível constatar que, se em "Dois tipos narcisistas" a expressão couraça narcísica não parece indicar a existência de uma estrutura física, na continuidade da produção do autor as elaborações conceituais passam a apontar, de maneira crescente, uma visão que supõe a presença de uma formação concreta, uma estrutura com uma dimensão, também, somática. Em produções reichianas posteriores ao período abrangido por este estudo, esse caminho conceitual que vislumbra as dimensões somáticas e psíquicas dos fenômenos, de alguma forma já existente em textos aqui analisados, será fundamentado teoricamente, sobretudo, pela noção de unidade funcional soma-psique (Reich, 1949/2003; Rodrigues, 2009; Wagner, 2009).

Dentre os trabalhos focalizados neste estudo, merece destaque, no que diz respeito à conceituação de couraça, o artigo "O caráter genital e o caráter neurótico: a função econômico-sexual da couraça do caráter" (Reich, 1929/2001d). Neste, o autor assume a tese de que os seres vivos, em busca de adaptação e sobrevivência ao meio externo, naturalmente desenvolvem estruturas protetoras. Assim sendo, no modelo de estrutura mais próximo ao polo da saúde, o caráter genital, a formação defensiva tem a possibilidade de se fazer presente e, também, de não permanecer ativa, isso em função das circunstâncias externas. Para qualificar tal estrutura protetora, que possui a capacidade de abertura e fechamento para o mundo, o autor usa a expressão couraça flexível.

Portanto, se o termo couraça empregado por Reich usualmente tem o sentido de defesa que se tornou crônica pelo seu enrijecimento, com a expressão couraça flexível, o autor indica a presença de uma formação capaz de alternar os estados de fechamento e de abertura para o mundo. Em outras palavras, há uma estrutura de defesa, mas ela não é marcada pela cronicidade. A consideração da flexibilidade da couraça também é possibilitada pela etimologia advinda do radical "couro", diferentemente de blindagem, por exemplo. O termo couraça permite que se pense no aspecto de proteção e maleabilidade própria do couro, além da tonicidade claramente orgânica. 
Outro ponto a considerar é que, para explicar a sua visão de couraça, Reich frequentemente utiliza exemplos retirados da biologia animal. Ao que parece, há um claro movimento do autor no sentido de alocar o homem no conjunto do universo animal, sendo a espécie humana um desenvolvimento, mas não uma ruptura com esse domínio, leitura que vai ao encontro do trabalho de Bedani (2013). Vale mencionar que, na sequência da obra reichiana, tal perspectiva se amplia de maneira muito clara, a ponto do autor utilizar largamente a expressão "animal humano" em seus escritos (ver, por exemplo, Reich, 1949/2003). O que fica patente neste estudo é o fato de que essa orientação, de alguma forma, já está esboçada em artigos publicados ainda na década de 1920, período em que Reich militou no campo psicanalítico.

Em uma tentativa de formulação mais completa, de posse dos ingredientes elencados nesta investigação, pode-se dizer que, destinada a exercer função protetora, a couraça constitui algo natural e inevitável, porém, dependendo do seu grau - em termos reichianos, da sua rigidez e cronicidade - essa estrutura pode comprometer o contato com o meio interno e externo, além de afetar a regulação libidinal do sujeito.

\section{The notion of armor in the work of Wilhelm Reich: publications from 1920 to 1933}

Abstract: This essay investigates the notion of armor in the first 13 years - from 1920 to 1933 - of the work of the analyst Wilhelm Reich (1897-1957), a period in which the author was connected to the International Psychoanalytical Association. The leading question was: what is (are) the meaning(s) of armor in Reich's thought? As to method, we have made a research in the writings of the then psychoanalyst according to the chronological sequence of his publications. Results: a) the armor is mentioned for the first time in 1922, in the essay "Two Narcissistic Types", in indication to a defense associated with character neurosis; b) at first, the armor was conceived in relation to the psychic field, but then slowly began to be addressed as part of the somatic field as well; c) aimed at having a protective function, the armor is something natural and inevitable, but as a structure it may end up harming the contact with the inside and the outside, besides affecting the subject's libidinal regulation.

Keywords: Wilhelm Reich, 1897-1957, armor, narcissistic armor, character armor, psychoanalysis.

\section{La notion de cuirasse dans l'œuvre de Wilhelm Reich: publications de 1920 à 1933}

Résumé: L'étude examine la notion de cuirasse dans les 13 premières années, de 1920 à 1933, de l'œuvre du psychanaliste Wilhelm Reich (1897-1957), période pendant laquelle l'auteur était membre de I'International Psychoanalytical Association [Association Internationale de Pschyanalyse]. Question directrice: quel est/ quels sont le/les sens de cuirasse dans la pensée de Reich? Méthode: nous menons des recherches sur les écrits de Reich, psychanalyste à cette époque-là, conformément à la séquence chronologique de la publication des travaux. Résultats: a) la cuirasse est mentionnée pour la première fois en 1922, dans l'article Deux types narcissiques, pour indiquer une défense associée au cadre des névroses caractérielles; b) en príncipe, elle est conçue dans la sphère psychique, mais graduellement, elle en vient à être considérée dans le cadre somatique également ; c) destinée à exercer une fonction protectrice, la cuirasse constitue quelque chose de naturel et d'inévitable, cependant cette structure peut arriver à compromettre le contact avec le milieu interne et externe et elle affecte aussi la régulation libidinale du sujet.

Mots-clés: Reich, Wilhelm, 1897-1957, cuirasse, cuirasse narcissique, cuirasse caractérielle, psychanalyse.

\section{La noción de coraza en la obra de Wilhelm Reich: publicaciones de 1920 a 1933}

Resumen: Este estudio investiga la noción de coraza en los primeros 13 años, de 1920 a 1933, de la obra del psicoanalista Wilhelm Reich (1897-1957), período en el cual este autor estuvo vinculado a la International Psychoanalytical Association. Según la pregunta de orientación ¿cuál es o cuáles son los sentidos de coraza en el pensamiento de Reich?, se investigó los escritos de Reich según el orden cronológico de su publicación. Los resultados fueron: a) se menciona la coraza por primera vez en 1922, en el artículo Dos tipos narcisísticos, para indicar una defensa asociada al cuadro de las neurosis de carácter; b) en un primer momento, se la concibe en la esfera psíquica, pero, gradualmente, pasa a considerarse también en el ámbito somático; c) destinada a ejercer función protectora, la coraza constituye algo natural e inevitable; sin embargo, esa estructura puede llegar a comprometer el contacto con el medio interno y el externo, además de afectar la regulación libidinal del sujeto.

Palabras clave: Reich, Wilhelm, 1897-1957, coraza, coraza narcisística, coraza del carácter, psicoanálisis. 


\section{Referências}

Albertini, P. (2011). Wilhelm Reich: percurso histórico e inserção do pensamento no Brasil. Boletim de Psicologia, 61(135), 159-176.

Almeida, B. H. P. (2012). A noção de couraça na obra de Wilhelm Reich: origens e considerações sobre o desenvolvimento humano (Dissertação de Mestrado). Instituto de Psicologia, Universidade de São Paulo, São Paulo.

Bedani, A. (2013). A relação entre sensação e produção de conhecimento na obra de Wilhem Reich (Tese de Doutorado). Instituto de Psicologia, Universidade de São Paulo, São Paulo.

Bergson, H. (1971). A evolução criadora (A. C. Monteiro, trad.). Rio de Janeiro, RJ: Opera Mundi. (Trabalho original publicado em 1907)

Boadella, D. (1985). Nos caminhos de Reich (E. R. B. Rebelo, M. S. Mourrão Netto \& I. Carvalho Filho, trads.). São Paulo, SP: Summus.

Cunha, A. G. (2009). Dicionário etimológico da língua portuguesa. São Paulo, SP: Lexikon.

Dadoun, R. (1978). Cien flores para Wilhelm Reich ( $\mathrm{R}$. Pochtar, trad.). Barcelona: Editorial Anagrama.

Etchegoyen, R. H. (1989). Fundamentos da técnica psicanalitica ( $2 \mathrm{a}$ ed., C. G. Fernandes, trad.). Porto Alegre, RS: Artes Médicas.

Freud, S. (2010). Além do princípio do prazer. In Sigmund Freud (P. C. de Souza, trad., Vol. 14, pp. 161-239). São Paulo, SP: Companhia das Letras (Trabalho original publicado em 1920)

Garcia, J. G. S. (2010). A couraça como currículo-oculto: um estudo da relação entre a rotina escolar e o funcionamento encouraçado (Tese de Doutorado). Faculdade de Educação, Universidade de São Paulo, São Paulo.

Houaiss, A., Villar, M. S., \& Franco, F. M. M. (2004). Dicionário Houaiss de língua portuguesa. Rio de Janeiro, RJ: Editora Objetiva.

Jones, E. (1979). Vida e obra de Sigmund Freud (M. A. M. Mattos, trad.). Rio de Janeiro, RJ: Zahar.

Laplanche, J., \& Pontalis, J.-B (1983). Vocabulário da psicanálise (7a ed., P. Tamen, trad.). São Paulo, SP: Martins Fontes.

Matthiesen, S. Q. (2007). Organização bibliográfica da obra de Wilhelm Reich: bases para o aprofundamento em diferentes áreas do conhecimento. São Paulo, SP: Annablume.

Rego, R. (2008). A vida é dura para quem é mole: considerações sobre aspectos psicológicos da hipotonia muscular (Monografia). Instituto de Análise Bioenergética de São Paulo, São Paulo. Recuperado de http://www.ibpb.com.br/RicardoRegohipotonia2008.pdf

Reich, W. (n.d.). Irrupção da moral sexual repressiva (S. Montarroyos \& J. S. Dias, trads., revisão de T. M. C. Estevaleto). São Paulo, SP: Martins Fontes (Trabalho original publicado em 1932)
Reich, W. (1970). Charakteranalyse (3a ed.). Frankfurt: Fischer Taschenbuch Verlag (Trabalho original publicado em 1933)

Reich, W. (1974). Psicologia de massa do fascismo (J. S. Dias, trad.). Porto: Escorpião. (Trabalho original publicado em 1933)

Reich, W. (1975). Two narcissistic types. In W. Reich, Early writings (P. Schmitz, trad., vo. 1, pp. 133-142). New York: Farrar, Straus and Giroux. (Trabalho original publicado em 1922)

Reich, W. (1976). People in trouble (P. Schmitz, trad.). New York: Farrar, Straus and Giroux. (Trabalho original publicado em 1953)

Reich, W. (1977a). Psicopatologia e sociologia da vida sexual (M. S. P., trad.). São Paulo, SP: Global. (Trabalho original publicado em 1927)

Reich, W. (1977b). Materialismo dialético e psicanálise (3a ed., J. J. M. Ramos, trad.). Lisboa: Presença. (Trabalho original publicado em 1929)

Reich, W. (1995). A função do orgasmo: problemas econômico-sexuais da energia biológica (M. G. Novak, trad.). São Paulo, SP: Brasiliense. (Trabalho original publicado em 1942)

Reich, W. (2001a). Análise do caráter (M. L. Branco \& M. M. Pecegueiro, trads.). São Paulo, SP: Martins Fontes. (Trabalho original publicado em 1933)

Reich, W. (2001b). Sobre a técnica de interpretação e de análise da resistência. In W. Reich, Análise do caráter (M. L. Branco \& M. M. Pecegueiro, trads., pp. 3350). São Paulo, SP: Martins Fontes. (Trabalho original publicado em 1927)

Reich, W. (2001c). Sobre a técnica de análise do caráter. In W. Reich, Análise do caráter (M. L. Branco \& M. M. Pecegueiro, trads., pp. 51-118). São Paulo, SP: Martins Fontes. (Trabalho original publicado em 1928)

Reich, W. (2001d). O caráter genital e o caráter neurótico: a função econômico-sexual da couraça do caráter. In W. Reich, Análise do caráter (M. L. Branco \& M. M. Pecegueiro, trads., pp. 165-185). São Paulo, SP: Martins Fontes. (Trabalho original publicado em 1929)

Reich, W. (2001e). A fobia infantil e a formação do caráter. In W. Reich, Análise do caráter (M. L. Branco \& M. M. Pecegueiro, trads., pp. 187-195). São Paulo, SP: Martins Fontes. (Trabalho original publicado em 1930)

Reich, W. (2001f). O caráter masoquista. In W. Reich, Análise do caráter (M. L. Branco \& M. M. Pecegueiro, trads., pp. 215-253). São Paulo, SP: Martins Fontes. (Trabalho original publicado em 1932)

Reich, W. (2001g). Indicações e perigos da análise do caráter. In W. Reich, Análise do caráter (M. L. Branco \& M. M. Pecegueiro, trads., pp. 119-123). São Paulo, SP: Martins Fontes. (Trabalho original publicado em 1933)

Reich, W. (2001h). Sobre o manejo da transferência. In W. Reich, Análise do caráter (M. L. Branco \& M. M. Pecegueiro, trads., pp. 125-144). São Paulo, SP: 
Martins Fontes. (Trabalho original publicado em 1933)

Reich, W. (2001i). A solução caracterológica do conflito sexual infantil. In W. Reich Análise do caráter (M. L. Branco \& M. M. Pecegueiro, trads., pp. 149-163). São Paulo, SP: Martins Fontes. (Trabalho original publicado em 1933)

Reich, W. (2001j). Algumas formas definidas de caráter. In W. Reich Análise do caráter (M. L. Branco \& M. M. Pecegueiro, trads., pp. 197-214). São Paulo, SP: Martins Fontes. (Trabalho original publicado em 1933)

Reich, W. (2003). O éter, Deus e o diabo. In W. Reich O éter, Deus e o diabo; A superposição cósmica (M. Hantower, trad., pp. 1-177). São Paulo, SP: Martins Fontes. (Trabalho original publicado em 1949)

Reich, W. (2008). A atitude dos pais a respeito do onanismo infantil (D. C. Avila \& P. Albertini, trads.). Transformações em Psicologia, 1(1), 102-111. (Trabalho original publicado em 1927)
Rodrigues, H. J. L. F. (2008). A relação entre o corpo e a mente nos escritos de Freud, Lacan e Reich: do fenômeno psicossomático à unidade soma-psiquê (Dissertação de Mestrado). Universidade Federal do Rio de Janeiro, Rio de Janeiro.

Silva, J. R. O. (2001). O desenvolvimento da noção de caráter no pensamento de Reich (Dissertação de Mestrado). Instituto de Psicologia, Universidade de São Paulo, São Paulo.

Wagner, C. M. (1996). Freud e Reich: continuidade ou ruptura? São Paulo, SP: Summus.

Wagner, C. M. (2009). Reich e a terapia psicorporal. In P. Albertini \& L. V. Freitas (Orgs.), Jung e Reich: articulando conceitos e práticas (pp. 148-157). Rio de Janeiro: Guanabara Koogan.

Weinmann, A. de O. (2002). Uma contribuição à história do movimento psicanalítico: a trajetória de Wilhelm Reich. Psicologia: Ciência e Profissão, 22(3), 14-19.

Recebido: 07/11/2013

Reformulação: 23/01/2014

Aceito: 06/04/2014 